\title{
Erratum: Laser Probing of the Plasma in the S-300 Facility (Plasma Phys. Rep. 28, 790 (2002))
}

\author{
Yu. G. Kalinin, V. A. Korel'skiü, E. V. Kravchenko, and A. Yu. Shashkov
}

The Editorial board of Plasma Physics Reports apologizes for the misprints in the paper by Yu. G. Kalinin et al. Laser Probing of the Plasma in the S-300 Facility, Plasma Phys. Rep. 28 (9), 790 (2002).

On page 790, in the list of authors, V. A. Korel'skiı̌ should instead read A. V. Korel'skiı̌.
On page 795, in the 26th line in the left column, the words "no larger than $3 . .$. " should instead read "no less than $3 . . . . "$

On page 795 , in the ninth line in the right column, the exponent 8 should be replaced by 7 . 